\title{
Cotrimoxazole plasma levels, dialyzer clearance and total removal by extended dialysis in a patient with acute kidney injury: risk of under- dosing using current dosing recommendations
}

\author{
Christian Clajus ${ }^{1}$, W Nikolaus Kühn-Velten², Julius J Schmidt ${ }^{1}$, Johan M Lorenzen ${ }^{1}$, Daniel Pietsch³ ${ }^{3}$ Gernot Beutel ${ }^{4}$
} and Jan T Kielstein ${ }^{1 *}$

\begin{abstract}
Background: Dosing of antibiotics in critically ill patients is challenging. It becomes even more difficult if renal or hepatic impairment ensue. Modern means of renal replacement therapy are capable of removing antibiotics to a higher rate than decades ago, leaving clinicians with a high degree of uncertainty concerning the dose of antibiotics in this patient population. Cotrimoxazole, a combination of trimethoprim (TMP) and sulfamethoxazole (SMX) is frequently used in the treatment of several infections including Pneumocystis jirovecii pneumonia (PCP).

Case presentation: Here we describe a patient with acute kidney injury in which we investigated the TMP and SMX levels during the course of an ICU stay. Cotrimoxazole was administered every six hours i.v. in a dose of TMP/SMX 15/75 mg/kg/day. Extended dialysis was performed with a high-flux dialyzer. Blood samples, as well as pre- and postdialyzer samples and aliquots of the collected spent dialysate were collected.

Observed peak concentrations (Cmax) were $7.51 \mathrm{mg} / \mathrm{l}$ for TMP and $80.80 \mathrm{mg} / \mathrm{l}$ for SMX. Decline of blood levels during extended dialysis (TMP 64\%; SMX 84\%) was mainly due to removal by the dialysis procedure, illustrated by the high dialyzer clearances (median of 4 extended dialysis sessions: TMP $94.0 / \mathrm{SMX} 51.0 \mathrm{ml} / \mathrm{min}$ ), as well as by the absolute amount of both substances in the collected spent dialysate (median of 6 extended dialysis sessions: TMP $556 \mathrm{mg} /$ SMX $130 \mathrm{mg}$ ). Within the limitation of a case report our data from 4 consecutive extended dialysis sessions suggest that this procedure substantially removes both TMP and SMX.
\end{abstract}

Conclusions: Dose reduction, which is usually advocated in patients with acute kidney injury under renal replacement therapy, might lead to significant under-dosing. Pharmacokinetic studies for TMP/SMX dosing in this patient population are necessary to allow adequate dosing.

Keywords: Antibiotics, Pharmacokinetics, Intensive care unit, Drug monitoring

\section{Background}

Cotrimoxazole, a fixed 1:5 combination of trimethoprim (TMP) and sulfamethoxazole (SMX), has a broad spectrum of activity against gram-positive and gram-negative bacteria as well as selected protozoa. It is approved for the treatment of acute exacerbation of chronic bronchitis, otitis media (in S. pneumoniae sensitive cases only), traveler's

\footnotetext{
* Correspondence: Kielstein@yahoo.com

'Department of Nephrology and Hypertension, Medical School Hannover, Hannover, Germany

Full list of author information is available at the end of the article
}

diarrhea, shigellosis, urinary tract infections, as well as for Pneumocystis jirovecii pneumonia (PCP) prophylaxis and treatment. After oral administration the drug is almost completely absorbed. The protein binding for TMP/SMX is $45 / 68 \%$. Both compounds are excreted in urine as metabolites and as unchanged drug. Consequently the normal half-life of TMP/SMX (6-17/9 hours) is prolonged in renal impairment. For the treatment of PCP a TMP/SMX dose of 15-20/75-100 mg/kg/day TMP/SMX divided in four doses per day for 14-21 days is recommended. In this patient population acute kidney injury is frequently seen [1].

\section{Biomed Central}

(c) 2013 Clajus et al.; licensee BioMed Central Ltd. This is an Open Access article distributed under the terms of the Creative Commons Attribution License (http://creativecommons.org/licenses/by/2.0), which permits unrestricted use, distribution, and reproduction in any medium, provided the original work is properly cited. 
However there is scarce data to guide dosing in patients undergoing renal replacement therapy. For patients on thrice weekly hemodialysis a dose of $5 / 20 \mathrm{mg} / \mathrm{kg}$ (TMP/ SMX) 3 times/wk after hemodialysis is recommended [2]. Currently the recommended dose in patients undergoing $\mathrm{CVVH}$ (continuous veno-venous hemofiltration) therapy is $5-15 \mathrm{mg} / \mathrm{kg} / \mathrm{d}$ TMP. A recent case report suggests that this dose is not sufficient when a filtration rate of $29 \mathrm{ml} / \mathrm{kg} / \mathrm{min}$ is used [3]. Moreover, there are no data on extended dialysis, a hybrid of continuous and intermittent renal replacement therapy, which is increasingly used throughout the world $[4,5]$. Extended dialysis removes various antibiotics more efficiently compared with standard intermittent hemodialysis three times a week or continuous renal replacement therapy [6-8]. To improve the pharmacokinetic information available to clinicians, as recently asked for by a KDIGO (Kidney Disease: Improving Global Outcomes) working group [9], we here report for the first time data on cotrimoxazole serum levels, dialyzer clearance and dialysate concentrations from a critically ill dialysis patient with PCP undergoing extended dialysis. Written informed consent was obtained from the patients legal representative (wife) for publication of this case report. A copy of the written consent is available for review by the Editor-in-Chief of this journal.

\section{Case presentation}

A 74 year old Caucasian male $(186 \mathrm{~cm}, 84 \mathrm{~kg})$ with a five year history of biopsy proven cANCA (cytoplasmic antineutrophil cytoplasmic antibody) positive vasculitis, leading to stable chronic kidney disease (KDOQI-stage 4), was admitted to the intensive care unit of our tertiary care hospital with tachypnea (respiratory rate of $20 / \mathrm{min}$ ) and a peripheral oxygen saturation of $88 \%$ under $12 \mathrm{l}$ oxygen per nasal cannula. The patient had been on immunosuppressive therapy for 5 years. Initially he received azathioprine and corticosteroids. After two years the immunosuppressive regime was changed to corticosteroids alone due to a carcinoma of the bladder. Two months prior to admission the patient developed a pulmonary relapse (hemoptysis) of his vasculitis and was treated with two bolus infusions of Cytoxan $\left(500 \mathrm{mg} / \mathrm{m}^{2}\right)$. Two weeks prior to the scheduled third i. v. bolus of Cytoxan the patient had complained about progressive dyspnea with unproductive cough. His general practitioner prescribed amoxicillin/clavulanic acid in response to elevated inflammatory markers. Aside from his vasculits his past medical history was significant for a myocardial infarction, mitral- and aortic valve insufficiency, arterial hypertension, thrombosis of the femoral vein, secondary hyperparathyreoidism and subacute atherosclerotic encephalopathy. In addition to the tachycardia the physical exam on admission to the intensive care unit was remarkable for a $2 / 6$ systolic murmur.
His blood pressure was $128 / 64 \mathrm{mmHg}$, heart rate 79 $\mathrm{bpm}$ and auricular temperature $36.2^{\circ} \mathrm{C}$. Chest X-ray showed a marked interstitial pneumonitis. Material obtained during bronchoscopy confirmed the diagnosis of PCP. Antibiotic therapy with TMP $800 \mathrm{mg} /$ day and SMX $4 \mathrm{~g} /$ day [respectively TMP: $10 \mathrm{mg} / \mathrm{kg} /$ day and SMX: $48 \mathrm{mg} / \mathrm{kg} /$ day] divided in four doses was started. In addition the patient received prednisolone at a dose of $25 \mathrm{mg}$ every 6 hours. Despite this therapy the patient deteriorated under non-invasive patient's ventilation and therefore needed mechanical ventilation. Concomitantly he developed acute on chronic oliguric kidney injury. Extended dialysis was performed (mean daily dialysis dose $74.4 \pm 12.6 \mathrm{l}$ ), which represents the institutional standard of care. In response to expected additional clearance by the dialysis the antibiotic dosages were adjusted to TMP $1.28 \mathrm{~g} /$ day and SMX $8 \mathrm{~g} /$ day [respectively TMP: $15 \mathrm{mg} / \mathrm{kg} /$ day and SMX: $95 \mathrm{mg} / \mathrm{kg} /$ day]. Two days after therapy initiation the patient stabilized and was extubated. A repeated bronchoscopy was negative for pneumocystis jirovecii infection and the dose was reduced to TMP $640 \mathrm{mg} /$ day and SMX $3.2 \mathrm{~g} /$ day [respectively TMP: $7 \mathrm{mg} / \mathrm{kg} /$ day and SMX: $38 \mathrm{mg} / \mathrm{kg} /$ day]. Extended dialysis was continued due to persisting kidney injury. In the further course the respiratory situation worsened due to viral and bacterial superinfection (herpessimplex; pseudomonas; gram-positive cocci), requiring re-intubation. The patient could not be weaned from mechanical ventilation and continuously required inotropic substances. Subsequently the patient suffered a myocardial reinfarction and died 35 days after admission on our intensive care unit.

For the determination of TMP/SMX levels blood samples were collected after drug infusion, prior to dialysis, under dialysis and post dialysis. Trimethoprim and sulfamethoxazole were quantified in parallel in serum specimens. After protein precipitation with acetonitrile/ methanol, matrix components were separated by isocratic reverse-phase HPLC (high-performance liquid chromatography), and specific molecule fragments were detected and quantified after electrospray ionisation in a PESciex API2000 triple-quadrupole mass spectrometer. Dialysates were analogously analyzed by HPLC-MSMS. The lower limit of detection was $0.1 \mathrm{mg} / \mathrm{l}$ for both substances, and the interassay $\mathrm{CV}$ (coefficient of variation) was $10.3 \%$ for TMP and $9.9 \%$ for SMX, respectively. EDD (extended daily dialysis) was performed using the 751 GENIUS ${ }^{\circledR}$ batch dialysis system (Fresenius Medical Care, Bad Homburg, Germany) with a polysulphone high-flux dialyzer (F60S, surface area $1.3 \mathrm{~m}^{2}$, Fresenius Medical Care, Bad Homburg, Germany) as previously described [7]. The technical details of the system are explained elsewhere [10]. The average dialysis time during this investigation was $442 \pm 101 \mathrm{~min}$, and mean 
blood and counter current dialysate flow was $170 \pm 41$ $\mathrm{ml} / \mathrm{min}$. Vascular access was achieved by a double lumen catheter inserted in the internal jugular vein. The dialyzer clearance was estimated from concentrations before $\left(C_{\text {in }}\right)$ and directly after $\left(C_{\text {out }}\right)$ the dialysis membrane as $\mathrm{CL}_{\text {dial }}=\left(\mathrm{Fl}_{\text {in }} \cdot \mathrm{C}_{\text {in }}-\mathrm{Fl}_{\text {out }} \cdot \mathrm{C}_{\text {out }}\right) / \mathrm{C}_{\text {in }}$, where the plasma flow in $\left(\mathrm{Fl}_{\text {in }}\right)$ and out $\left(\mathrm{Fl}_{\text {out }}\right)$ of the dialyzer was estimated using the blood flow, hematocrit and ultrafiltration rate. In addition, total drug removal was estimated by measuring drug concentration in the spent dialysate, since the GENIUS-system permits easy access to the entire amount of substances that had been removed during a dialysis session. All samples were centrifuged at $1300 \mathrm{~g}$ for $10 \mathrm{~min}$ at $4^{\circ} \mathrm{C}$. Plasma was separated and stored at $-80^{\circ} \mathrm{C}$ until analysis. Data are presented as absolute numbers, percentages, and means with corresponding standard deviations (SD) unless otherwise stated.

Peak concentrations (immediately after infusion was finished and before RRT was initiated) for TMP was $7.51 \pm 1.15 \mathrm{mg} / \mathrm{l}$ and for SMX $80.80 \pm 3.8 \mathrm{mg} / \mathrm{l}$ in a study period of three consecutive days with a dose of TMP/ SMX $15 / 75 \mathrm{mg} / \mathrm{kg} /$ day (Figure 1). Concentrations fell to $5.13 \pm 1.79 \mathrm{mg} / \mathrm{l}$ for TMP $(p=0.08)$ and $38.73 \pm 6.61 \mathrm{mg} / \mathrm{l}$ for SMX $(p=0.007)$ at the end of dialysis. The dialyzer clearances from 4 consecutive extended dialysis treatments are depicted in Figure 2A. They were 94.0 \pm 20.2 $\mathrm{ml} / \mathrm{min}$ for TMP and $51.0 \pm 18.8 \mathrm{ml} / \mathrm{min}$ for SMX . Additionally the average total amount of removed drug was $781 \mathrm{mg}$ for TMP and $766 \mathrm{mg}$ for SMX (median TMP 565 (436 - 1234) mg, SMX 130 (104 - 247) mg (respectively $55 \%$ for TMP and 55\% for SMX of the previously infused dose) per treatment session (Figure 2B).

\section{Conclusions}

Cotrimoxazole is one of the most poorly studied drugs when it comes to dosing under renal replacement therapy. This is especially surprising given the fact that it is used for half a century. The first report on the influence of

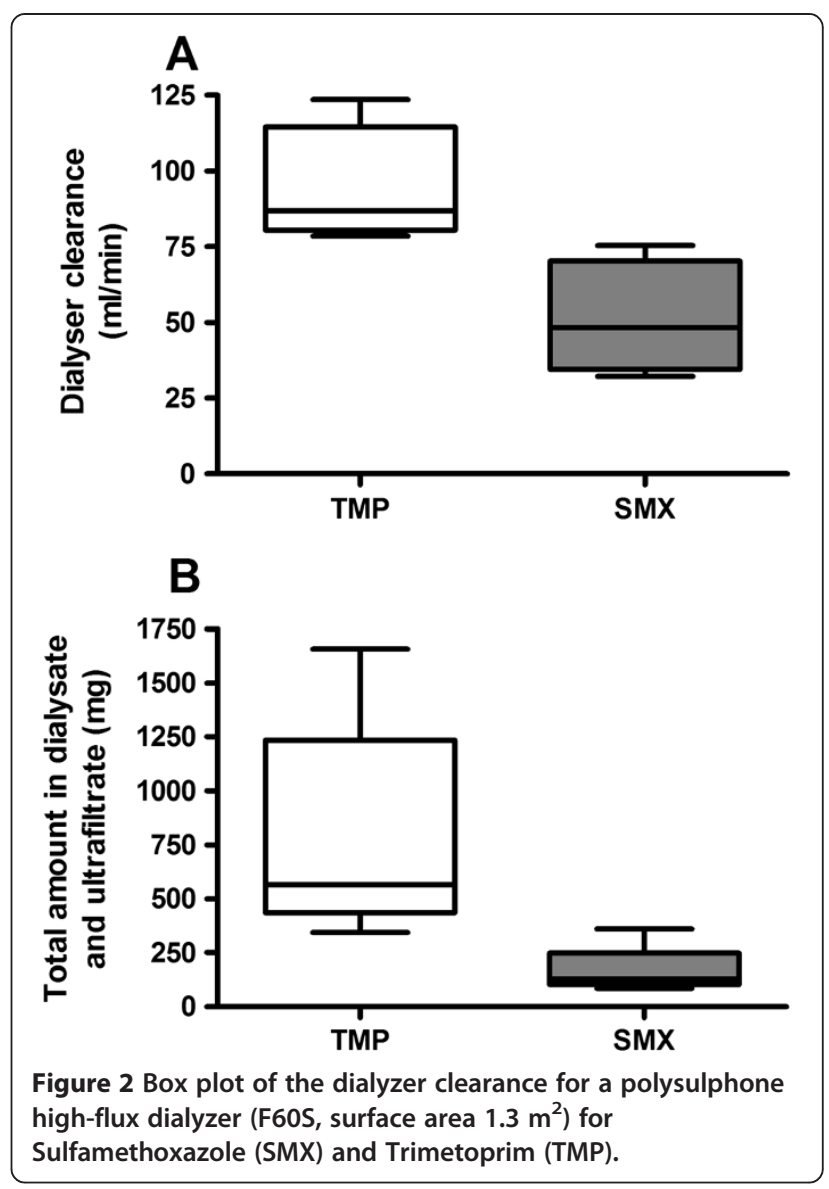

hemodialysis on TMP/SMX included 3 patients that received twice weekly dialysis for 13 hours using a modified KIIL dialyzer (surface area $1.0 \mathrm{~m}^{2}$ ) indicating that TMP is not removed as is SMX [11]. Back then patients dialyzed twice weekly for 13 hours. Craig and Kunin studied four hemodialysis patients, they did not however provide any data on the coordinates of the dialysis procedure itself, making the interpretation of their data impossible [12].

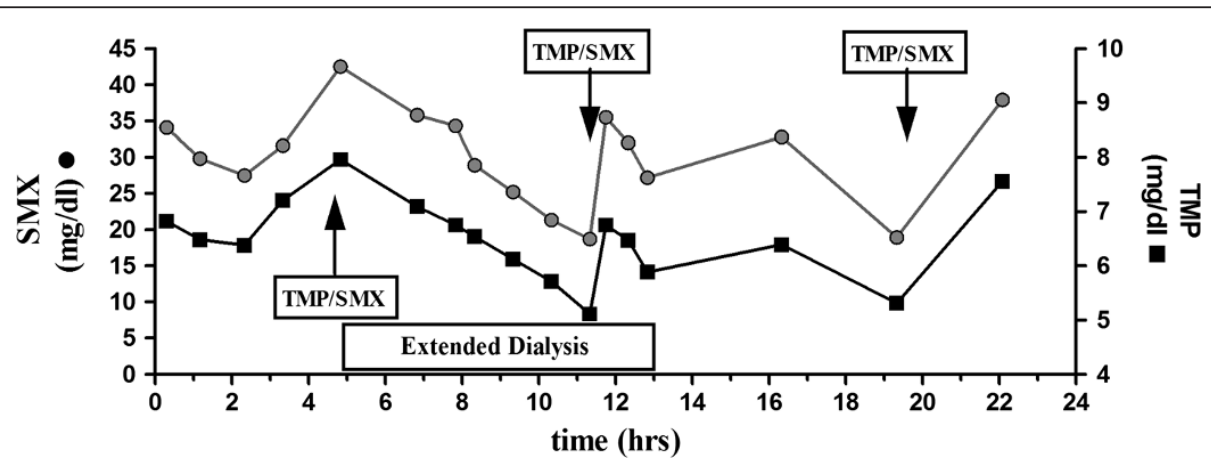

Figure 1 Time course of plasma Sulfamethoxazole (SMX) and Trimetoprim (TMP) over a time period of 24 hours of an ICU patient with acute on chronic renal failure undergoing extended dialysis. TMP/SMX were administration indicated by arrows and TMP/SMX. Width of boX for extended dialysis corresponds to the time of the procedure. 
Table 1 Coordinates of PK parameters and dialysis procedure of our patient undergoing extended dialysis compared to the data from patients undergoing intermittent hemodialysis and CVVH from the literature

\begin{tabular}{llll}
\hline TMP /SMX & ED & IHD [13] & CVVHDF [3] \\
$\mathbf{n}$ & $\mathbf{1}$ & $\mathbf{1 6}$ & $\mathbf{2}$ \\
\hline Administred dose $(\mathrm{mg})$ & $\mathbf{8 0 0 / 4 0 0 0}$ & $160 / 800$ & $160 / 800$ \\
C $_{\max }(\mathrm{mg} / \mathrm{l})$ & $\mathbf{7 . 5 1 / 8 0 . 8}$ & $1.93 / 41.8$ & $3.73 / 33.4$ \\
Blood flow $(\mathrm{ml} / \mathrm{min})$ & $\mathbf{1 4 0}$ & 200 & $150 \& 180$ \\
Dialyzer clearance $(\mathrm{ml} / \mathrm{min})$ & $\mathbf{9 4 / 5 1}$ & $38 / 42$ & $26 / 29$ \\
Dialyzer surface $\left(\mathrm{m}^{2}\right)$ & $\mathbf{1 . 3}$ & 1.0 & 1.8 \\
Dialyzer & $\mathbf{P o l y s u l p h o n e}$ & Cuprophane & Polysuphone \\
Treatment time $(\mathrm{min})$ & $\mathbf{4 4 2}$ & 240 & Not reported \\
\hline
\end{tabular}

The Current dosing recommendation in chronic hemodialysis patients is therefore solely based on a 1987 paper by Nissenson et al. [13]. They investigated 16 stable hemodialysis patients that were all dialyzed for 4 $\mathrm{h}$ with a $1.0 \mathrm{~m}^{2}$ cuprophane dialyzer at a blood flow of $200 \mathrm{ml} / \mathrm{min}$ and a dialysate flow of $500 \mathrm{ml} / \mathrm{min}$. Dialysis clearance averaged $38 \mathrm{ml} / \mathrm{min}$ for TMP and $42 \mathrm{ml} / \mathrm{min}$ for SMX. About 44\% of the administered TMP and 57\% of the administered SMX were removed during dialysis. Therefore, $50 \%$ of the maintenance dose of TMP-SMX should be supplemented after each dialysis session. Recently, Curkovic et al. reporting two patients undergoing CVVHD (continuous veno-venous hemodialysis) showed clearances of TMP (21.5-28.9 $\mathrm{ml} / \mathrm{min})$ that were within the range observed in patients with normal renal function $(20-80 \mathrm{ml} / \mathrm{min})$. SMX clearance in CVVHDF (continuous veno-venous hemodiafiltration) showed a high variability $(18.7,26.7$, and $42.6 \mathrm{ml} / \mathrm{min}$ ) and exceeded renal clearance values in normal renal function (1-5 $\mathrm{ml} / \mathrm{min})$ [3] (Table 1).

Our patient underwent extended dialysis due to oliguric kidney injury and volume overload. We found peak concentrations of both drugs being in the upper recommended range (TMP $7.51 \pm 1.15 \mathrm{mg} / \mathrm{l}$ and SMX $80.80 \pm 3.8 \mathrm{mg} / \mathrm{l})$ with administration of the standard dose for TMP and SMX for patients with normal renal function [respectively TMP: $15 \mathrm{mg} / \mathrm{kg} /$ day and SMX: 95 $\mathrm{mg} / \mathrm{kg} /$ day]. After dialysis session the concentrations declined rashly. These results imply a significant drug elimination compared with the above described dialysis modality. This hypothesis is confirmed by the calculated dialyzer clearances (TMP $94.0 \pm 20.2 \mathrm{ml} / \mathrm{min}$ and SMX $51.0 \pm 18.8 \mathrm{ml} / \mathrm{min}$; Figure 2). These results exceed by far the renal clearance under physiological conditions. In a work from Paap clearances varied from 1.13 - 103.6 $\mathrm{ml} / \mathrm{min}$ for TMP and $0.4-18.29 \mathrm{ml} / \mathrm{min}$ for active SMX in patients with normal renal function [14]. Some explanation may be given when comparing the actual dialysis modalities to the ones used 30 years ago. The blood flow is comparable and the counter current dialysate flow is even less in this study, but the dialyzer membrane has changed to a high-flux-dialyzer with a significant larger surface area. Furthermore, the effective dialysis time $(442 \pm 101 \mathrm{~min})$ combined with a daily therapy could explain the highly efficient elimination of TMP and SMX.

In conclusion the high elimination rate of TMP and SMX in our patient undergoing extended daily dialysis suggests that maybe old dosing regimens from the time of less efficient renal replacement therapies might not yield adequate dosing. This potential problem is aggravated by the fact that drug monitoring for TMP/SMX is not recommended and determination of a successful therapy is mainly based on clinical parameters [15]. Further pharmacokinetic studies should be performed to develop dosing recommendations for TMP/SMX that keep up with the efficacy of modern renal replacement therapies.

\section{Consent}

Written informed consent was obtained from the patient's legal representative for publication of this Case report and any accompanying images. A copy of the written consent is available for review by the Series Editor of this journal.

\section{Competing interests}

The authors declare that they have no competing interests.

\section{Authors' contributions}

NKV conducted the measurement of TMP/SMX. CC, GB, JL and JTK were the treating physicians of the patient reported. CC, JTK and DP evaluated the test results. All of the authors have participated in the discussion and in writing of the submitted manuscript. All authors read and approved the final manuscript

\section{Acknowledgement}

The publication of the study is supported by the DFG-project "Open Access Publication".

\section{Author details}

${ }^{1}$ Department of Nephrology and Hypertension, Medical School Hannover, Hannover, Germany. ${ }^{2}$ Medical Laboratory Bremen, Bremen, Germany. ${ }^{3}$ Institute of Clinical Chemistry, Medical School Hannover, Hannover, Germany. ${ }^{4}$ Department of Hematology, Hemostasis, Oncology, and Stem Cell Transplantation, Medical School Hannover, Hannover, Germany. 


\section{References}

1. Cohen SD, Chawla LS, Kimmel PL: Acute kidney injury in patients with human immunodeficiency virus infection. Curr Opin Crit Care 2008, 14(6):647-653.

2. Heintz BH, Matzke GR, Dager WE: Antimicrobial dosing concepts and recommendations for critically ill adult patients receiving continuous renal replacement therapy or intermittent hemodialysis. Pharmacotherapy 2009, 29(5):562-577.

3. Curkovic I, et al: Trimethoprim/Sulfamethoxazole pharmacokinetics in two patients undergoing continuous venovenous hemodiafiltration. Ann Pharmacother 2010, 44(10):1669-1672.

4. Fliser D, Kielstein JT: Technology Insight: treatment of renal failure in the intensive care unit with extended dialysis. Nat Clin Pract Nephrol 2006, 2(1):32-39.

5. Kielstein JT, Schiffer M, Hafer C: Back to the future: extended dialysis for treatment of acute kidney injury in the intensive care unit. J Nephrol 2010, 23(5):494-501.

6. Czock D, et al: Pharmacokinetics of moxifloxacin and levofloxacin in intensive care unit patients who have acute renal failure and undergo extended daily dialysis. Clin J Am Soc Nephrol 2006, 1(6):1263-1268.

7. Kielstein JT, et al: Dosing of daptomycin in intensive care unit patients with acute kidney injury undergoing extended dialysis-a pharmacokinetic study. Nephrol Dial Transplant 2010, 25(5):1537-1541.

8. Lorenzen JM, et al: Pharmacokinetics of ampicillin/sulbactam in critically ill patients with acute kidney injury undergoing extended dialysis. Clin J Am Soc Nephrol 2012, 7(3):385-390.

9. Matzke GR, et al: Drug dosing consideration in patients with acute and chronic kidney disease-a clinical update from kidney disease: improving global outcomes (KDIGO). Kidney Int 2011, 80(11):1122-1137.

10. Fliser $\mathrm{D}$, Kielstein JT: A single-pass batch dialysis system: an ideal dialysis method for the patient in intensive care with acute renal failure. Curr Opin Crit Care 2004, 10(6):483-488.

11. Gahl G, et al: Kinetic studies on a chemotherapeutic drug combination (sulfamethoxazole and trimethoprim) in chronic kidney insufficiency. Verh Dtsch Ges Inn Med 1971, 77:1017-1019.

12. Craig WA, Kunin CM: Trimethoprim-sulfamethoxazole: pharmacodynamic effects of urinary $\mathrm{pH}$ and impaired renal function. Studies in humans. Annals of internal medicine 1973, 78(4):491-497.

13. Nissenson AR, Wilson C, Holazo A: Pharmacokinetics of intravenous trimethoprim-sulfamethoxazole during hemodialysis. Am J Nephrol 1987 7(4):270-274.

14. Paap CM, Nahata MC: Clinical use of trimethoprim/sulfamethoxazole during renal dysfunction. DICP: the annals of pharmacotherapy 1989, 23(9):646-654.

15. Wharton JM, et al: Trimethoprim-sulfamethoxazole or pentamidine for Pneumocystis carinii pneumonia in the acquired immunodeficiency syndrome. A prospective randomized trial. Ann Intern Med 1986, 105(1):37-44.

doi:10.1186/2050-6511-14-19

Cite this article as: Clajus et al:: Cotrimoxazole plasma levels, dialyzer clearance and total removal by extended dialysis in a patient with acute kidney injury: risk of under-dosing using current dosing recommendations. BMC Pharmacology and Toxicology 2013 14:19.

\section{Submit your next manuscript to BioMed Central and take full advantage of:}

- Convenient online submission

- Thorough peer review

- No space constraints or color figure charges

- Immediate publication on acceptance

- Inclusion in PubMed, CAS, Scopus and Google Scholar

- Research which is freely available for redistribution 